\title{
Effects of Irradiation Patterns and Light Quality of Red and Blue Light-Emitting Diodes on Growth of Leaf Lettuce (Lactuca sativa L.“Greenwave”)
}

\author{
Yuichiro KunO ${ }^{1}$, Hiroshi Shimizu ${ }^{2}$, Hiroshi NAKASHIMA², Juro MiYASAKA ${ }^{2}$ and Katsuaki OHDoI ${ }^{2}$ \\ ' Suntory Holdings Limited, 2-3-3 Daiba, Minato-ku, Tokyo 135-8631, Japan \\ ${ }^{2}$ Graduate School of Agriculture, Kyoto University, Kyoto 606-8502, Japan
}

(Received August 20, 2016; Accepted March 21, 2017)

\begin{abstract}
Effects of the irradiation patterns of red and blue LED lights on the growth of leaf lettuce were investigated. Seedlings of leaf lettuce (Lactuca sativa L. "Greenwave") were transplanted and grown under four irradiation patterns consisted of simultaneous irradiation of blue light with PPFD of $120 \mu \mathrm{mol} \mathrm{m}^{-2} \mathrm{~s}^{-1}$ and red light with PPFD of $120 \mu \mathrm{mol} \mathrm{m}^{-2} \mathrm{~s}^{-1}$ during a $12 \mathrm{~h}$ photoperiod (RB $12 \mathrm{~h} /$ dark period $12 \mathrm{~h}$ ), $4 \mathrm{~h}$ shifted irradiation of blue light (R $4 \mathrm{~h} / \mathrm{RB} 8 \mathrm{~h} / \mathrm{B} 4 \mathrm{~h} /$ dark period $8 \mathrm{~h}$ ), $8 \mathrm{~h}$ shifted irradiation of blue light ( $8 \mathrm{~h} / \mathrm{RB} 4 \mathrm{~h} / \mathrm{B} 8 \mathrm{~h} /$ dark period $4 \mathrm{~h}$ ), and alternating irradiation ( $\mathrm{R} 12 \mathrm{~h} / \mathrm{B} 12 \mathrm{~h}$ ). The results demonstrated that larger shifts in irradiation times between red and blue lights led to increasing fresh/dry weight of leaf lettuce. A similar trend was observed under the irradiation patterns that replaced the red and blue. An experiment to examine the effects of simultaneous or alternating irradiation of red and blue light under equal day length and light integral was also conducted. As a result, alternating red and blue light irradiation produced better results compared to simultaneous treatment for Greenwave in both experiments.
\end{abstract}

Keywords : alternating irradiation, growth promotion, plant factory, shift of irradiation, simultaneous irradiation

\section{INTRODUCTION}

Plant factories are enclosed agricultural facilities with artificially controlled environments, permit plant cultivation under regulated growth environments. Under such conditions, several irradiation patterns can be applied to stimulate plant growth, and constant atmospheric conditions can be maintained. Plant factories thus represent suitable environments for research relating to the effects of certain stimuli on plants, with the goal of increasing the production of high-quality vegetables. However, plant factories also have several limitations owing to the high costs associated with facility design, operation, and maintenance. For economic reasons, therefore, cultivation technologies that reduce power consumption while improving vegetable production under commercially operated plant factory must be established.

Light quality has previously been shown to influence plant growth and morphogenesis, and these responses differ between plant species. Lettuce is a popular nutritious leafy vegetable, which can easily be cultivated and is used as a model crop in many types of plant factory research. For example, it was found that emerging lettuce leaves were elongated under exposure to red light, and the total leaf area available for light absorption was limited. In contrast, the addition of blue light resulted in leaf expansion and unrolling, which enhanced light exposure (Hanyu and Shoji, 2000; Stutte et al., 2009). Inada and Yabumoto (1989) reported that light quality, day length, and periodic tempera- ture variation influence the growth of lettuce and radish plants. Simultaneous irradiation with red and blue lights was superior to irradiation with either red or blue light alone in terms of fresh weight accumulation of lettuce (Shimokawa et al., 2013). Similarly, the higher the intensity of red light of 219 and $209 \mu \mathrm{mol} \mathrm{m}{ }^{-2} \mathrm{~s}^{-1}$ under mixed light of red and blue, the greater the fresh weight accumulation compared with the red light of $192 \mu \mathrm{mol} \mathrm{m} \mathrm{m}^{-2} \mathrm{~s}^{-1}$ (Matsumoto et al., 2010). Moreover, the dry weight accumulation of red leaf lettuce under nocturnal blue light was promoted under the artificial lighting (Ebisawa et al., 2008). Furthermore, it was found that increases in blue light cause great inhibition of stem extension and thickening of leaf (Hanyu and Shoji, 2002; Saito et al., 2012).

In addition to these studies, difference in irradiation patterns of light has recently been shown to influence plant growth. Shimokawa et al. (2013) examined the effects of single, simultaneous and alternating irradiations with red and blue LED light on the growth rates of leaf lettuce demonstrated that alternating irradiation with red and blue light was better irradiation pattern for enhanced the growth rate of three varieties of leaf lettuce (Lactuca sativa L. var crispa), Summer Surge, Black Rose, and Green Span. Previous studies reported the simple comparison between simultaneous and alternative irradiation of red and blue light, on the other hand, we focused on the effect of shift in irradiation times of red and blue light by 4 and $8 \mathrm{~h}$ in addition of complete alternative irradiation. We also evaluated the effects of simultaneous or alternating irradiation of red and blue light under equal day length and light integral by

Corresponding author: Hiroshi Shimizu, fax: + 81-75-753-6165, e-mail : hshimizu@kais.kyoto-u.ac.jp 
cultivating leaf lettuce under fully controlled plant factory conditions using red and blue LED lights.

The final goal of this study was to determine the optimum red and blue irradiation patterns that maximize the growth of Greenwave under the same energy consumption for lighting.

\section{MATERIALS AND METHODS}

\section{Plant materials and conditions}

Leaf lettuce (Lactuca sativa L."Greenwave") seeds were sown on a water-soaked sponge, and seedlings were raised under a white LED light source $(\mathrm{PPFD}=100 \mu \mathrm{mol}$ $\mathrm{m}^{-2} \mathrm{~s}^{-1}$, light period/dark period $=16 \mathrm{~h} / 8 \mathrm{~h}, \mathrm{NE02-000089}$ (01); Shibasaki, Saitama, Japan). After 9 d, the germinated seedlings were transplanted into growth chambers set up within a deep flow technique (DFT) hydroponics culture system with planting density of 10 plants per $60 \times 60 \mathrm{~cm}$. Daytime and nighttime ambient air temperatures in the cultivation panel were set to $23^{\circ} \mathrm{C}$ and $20^{\circ} \mathrm{C}$, respectively, with the nutrient solution temperature set to $18^{\circ} \mathrm{C}$. The Electro Conductivity (EC) and $\mathrm{pH}$ were maintained at $1.2 \pm 0.1$ $\mathrm{dS} \mathrm{m} \mathrm{m}^{-1}$ and $6.0 \pm 0.3$, respectively. Ten lettuce plants were cultivated per treatment and harvested $21 \mathrm{~d}$ after transplanting.

\section{Light treatment}

In all experiments, we used red LED lights and blue LED lights (UL0009\#01-0R, wavelength red $=660 \mathrm{~nm}$, blue $=450$ nm; SHOWA DENKO K.K., Tokyo, Japan).
Experiment 1 (1-1[RB], 1-2[BR], 1-3[RR])

Two different experiments shifting the irradiation time of red and blue light (Fig. 1, Experiment 1-1 [RB], 1-2 [BR]) were conducted, and an experiment with similar shifting pattern using the same red light (Fig. 1, Experiment $\left.1^{-3}[\mathrm{RR}]\right)$ were performed to estimate the effect of light color (red and blue) in alternating irradiation.

Experiment 1-1 [RB]

All plants were illuminated using red and blue LEDs programmed to provide 12-h irradiation, and photosynthetic photon flux density (PPFD) of $120 \mu \mathrm{mol} \mathrm{m} \mathrm{m}^{-2} \mathrm{~s}^{-1}$ at cultivation panel.

Treatment RB1 included simultaneous irradiation under red and blue light during a $12 \mathrm{~h}$ light period (RB 12 $\mathrm{h}$ /dark period $12 \mathrm{~h}$ ). For treatments RB2 and RB3, the irradiation time with the red light was fixed whereas that of the blue light was gradually shifted by $4 \mathrm{~h}$. Treatment RB2 included irradiation only under red light for $4 \mathrm{~h}$, then both red and blue light for $8 \mathrm{~h}$, followed by blue light only for $4 \mathrm{~h}$ (R $4 \mathrm{~h} / \mathrm{RB} 8 \mathrm{~h} / \mathrm{B} 4 \mathrm{~h} /$ dark period $8 \mathrm{~h}$ ). In treatment RB3, blue light shifted additional $4 \mathrm{~h}$, and consisted of irradiation only under red light for $8 \mathrm{~h}$, then both red and blue light for $4 \mathrm{~h}$, followed by blue light for only $8 \mathrm{~h}(\mathrm{R} 8 \mathrm{~h} / \mathrm{RB} 4 \mathrm{~h} / \mathrm{B} 8$ $\mathrm{h} /$ dark period $4 \mathrm{~h}$ ). In treatment RB4, lettuce plants were irradiated with alternating red and blue light. Hence, irradiation was provided by red light for $12 \mathrm{~h}$ and then blue light for the next $12 \mathrm{~h}(\mathrm{R} 12 \mathrm{~h} / \mathrm{B} 12 \mathrm{~h})$.

\section{Experiment $1^{-2}[B R]$}

The blue light was fixed in experiment $1-2[B R]$ using
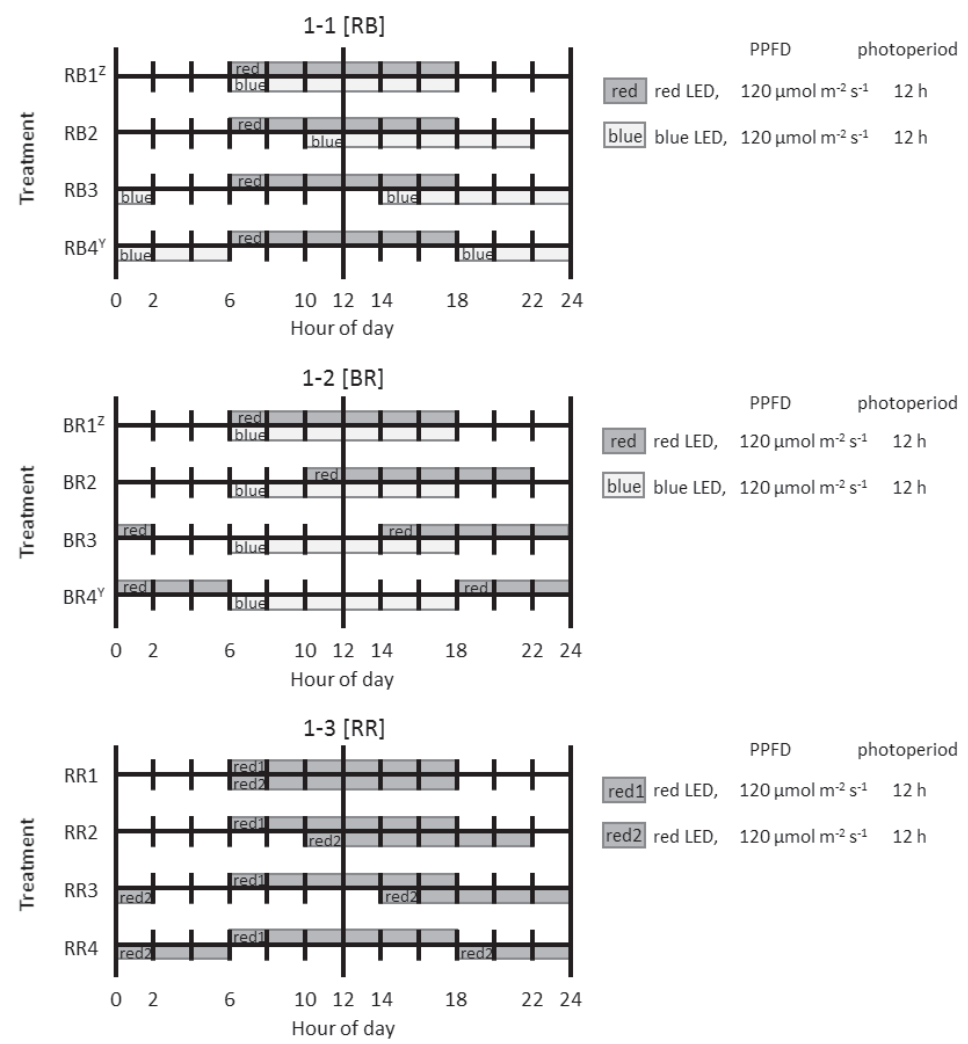

Fig. 1 Illustration of irradiation patterns of experiments $1-1[R B], 1-2[B R]$ and $1-3[R R]$.

${ }^{\mathrm{z}}$ Treatments RB1 and BR1 were the same simultaneous irradiation.

${ }^{\mathrm{Y}}$ Treatments RB4, BR4 and 2D in Fig. 2 were the same alternating irradiation. 
the same red and blue LEDs in the Experiment 1-1[RB] which provide 12-h irradiation, and photosynthetic photon flux density (PPFD) of $120 \mu \mathrm{mol} \mathrm{m} \mathrm{m}^{-2}$. Treatment BR1 included simultaneous irradiation under red and blue light during a $12 \mathrm{~h}$ light period (RB $12 \mathrm{~h}$ /dark period $12 \mathrm{~h}$ ). In treatments $\mathrm{BR} 2$ and $\mathrm{BR} 3$, in contrast to experiment $1^{-1}$ $[R B]$, the irradiation time under blue light was fixed and that of the red light was shifted by $4 \mathrm{~h}$ gradually. Treatment BR2 was composed of irradiation only under blue light for $4 \mathrm{~h}$, then both red and blue light for $8 \mathrm{~h}$, followed by red light for only $4 \mathrm{~h}$ (B 4 h/RB 8 h/R 4 h/dark period $8 \mathrm{~h}$ ). Treatment BR3 included irradiation only under blue light for $8 \mathrm{~h}$, then both red and blue light for $4 \mathrm{~h}$, followed by red light only for $8 \mathrm{~h}$ (B 8 h/RB 4 h/R 8 h/dark period $4 \mathrm{~h}$ ). In treatment 4 , lettuce plants were irradiated with alternating red and blue light. Hence, irradiation was provided by red light for $12 \mathrm{~h}$ and then blue light for the next $12 \mathrm{~h}(\mathrm{R} 12 \mathrm{~h} / \mathrm{B} 12 \mathrm{~h})$.

\section{Experiment [RR]}

Treatment RR1 plants were irradiated with highintensity $\left(240 \mu \mathrm{mol} \mathrm{m}^{-2} \mathrm{~s}^{-1}\right)$ red light (HR) over a 12 -h period (HR $12 \mathrm{~h} /$ dark period $12 \mathrm{~h}$ ). In treatments RR2 and RR3, the irradiation time with red light was gradually shifted by $4 \mathrm{~h}$. Treatment RR2 consisted of only red light for $4 \mathrm{~h}$, then high-intensity red light for $8 \mathrm{~h}$, followed by red light only for $4 \mathrm{~h}$ (R $4 \mathrm{~h} / \mathrm{HR} 8 \mathrm{~h} / \mathrm{R} 4 \mathrm{~h} /$ dark period $8 \mathrm{~h}$ ). Treatment RR3 included only red light for $8 \mathrm{~h}$, then highintensity red light for $4 \mathrm{~h}$, followed by red light only for 8 h (R 8 h/HR 4 h/R 8 h/dark period 4 h). In treatment RR4, the lettuce plants were irradiated solely with red light for the entire 24-h period ( $\mathrm{R} 24 \mathrm{~h}$ ).

\section{Experiment 2}

An experiment without dark period was conducted in experiment 2 to evaluate the effects of simultaneous or alternating irradiation of red and blue light under equal day length and light integral. Four irradiation patterns were examined and light treatments were set based on the following conditions (Fig. 2): all plants were irradiated with red and blue LEDs programmed to provide irradiation with red and blue light, respectively. Day length was integrated for $24 \mathrm{~h}$, and light intensities differed. Daily light integral of four irradiation patters was equal and set at $10.4 \mathrm{~mol} \mathrm{~m}^{-2}$.

Light intensities and irradiation times for each treatment were as follows:

Treatment 2A: red $60 \mu \mathrm{mol} \mathrm{m} \mathrm{m}^{-2} \mathrm{~s}^{-1}, 24 \mathrm{~h}$, blue $60 \mu \mathrm{mol} \mathrm{m} \mathrm{m}^{-2} \mathrm{~s}^{-1}, 24 \mathrm{~h}$

Treatment 2B: red $72 \mu \mathrm{mol} \mathrm{m}{ }^{-2} \mathrm{~s}^{-1}, 20 \mathrm{~h}$, blue $72 \mu \mathrm{mol} \mathrm{m} \mathrm{m}^{-2} \mathrm{~s}^{-1}, 20 \mathrm{~h}$

Treatment 2C: red $90 \mu \mathrm{mol} \mathrm{m}{ }^{-2} \mathrm{~s}^{-1}, 16 \mathrm{~h}$, blue $90 \mu \mathrm{mol} \mathrm{m} \mathrm{m}^{-2} \mathrm{~s}^{-1}, 16 \mathrm{~h}$

Treatment 2D: red $120 \mu \mathrm{mol} \mathrm{m} \mathrm{m}^{-2} \mathrm{~s}^{-1}, 12 \mathrm{~h}$, blue $120 \mu \mathrm{mol} \mathrm{m} \mathrm{m}^{-2}, 12 \mathrm{~h}$

Treatment $2 \mathrm{~A}$ was simultaneous irradiation under red and blue light over a 24-h light period (RB $24 \mathrm{~h}$ ). Treatment $2 \mathrm{~B}$ consisted of irradiation only under red light for $4 \mathrm{~h}$, then both red and blue light for $16 \mathrm{~h}$, followed by blue light only for $4 \mathrm{~h}(\mathrm{R} 4 \mathrm{~h} / \mathrm{RB} 16 \mathrm{~h} / \mathrm{B} 4 \mathrm{~h})$. Treatment $2 \mathrm{C}$ included irradiation only under red light for $8 \mathrm{~h}$, then both red and blue light for $8 \mathrm{~h}$, followed by blue light only for $8 \mathrm{~h}(\mathrm{R} 8 \mathrm{~h} / \mathrm{RB} 8 \mathrm{~h} / \mathrm{B} 8 \mathrm{~h})$. In treatment $2 \mathrm{D}$, lettuce plants were irradiated with alternating red and blue light. Hence, irradiation was provided by red light for $12 \mathrm{~h}$ and then blue light for the next $12 \mathrm{~h}(\mathrm{R} 12 \mathrm{~h} / \mathrm{B} 12 \mathrm{~h})$. All lettuce plants were cultivated for $21 \mathrm{~d}$ after transplanting.

Measurement and analysis

Growth parameters analyzed consisted of total fresh weight including root (total fresh weight), fresh weight of aerial parts, number of leaves, stem length, dry weight of aerial parts, dry matter ratio, SPAD, and stomata density (number of stomata per $1 \mathrm{~mm}^{2}$ ). Number of leaves was counted for the leave over 3-cm in length; stem length was defined as the length of the plant minus the roots and leaves; dry matter was measured after the lettuce plants were dried in a dryer at $103^{\circ} \mathrm{C}$ for $24 \mathrm{~h}$, with dry matter ratio calculated as dry weight of aerial parts $\div$ fresh weight of aerial parts $\times 100$; SPAD was defined as the cumulative measurements of 8 points selected from two bigger leaves of two plants; and stomatal number was defined as the cumulative measurements of 4 points of the third leaf.

To assess growth parameters under each condition, the means of 10 replicates \pm standard deviation (SD) were calculated. Ryan's multiple comparison test was performed using ANOVA4 software, with statistical significance was set at $P<0.05$.

\section{RESULTS}

\section{Results of experiment 1 ( $R B, B R, R R)$}

Tables 1 and 2 show that the shift of irradiation times of red and blue lights resulted in significant increases in

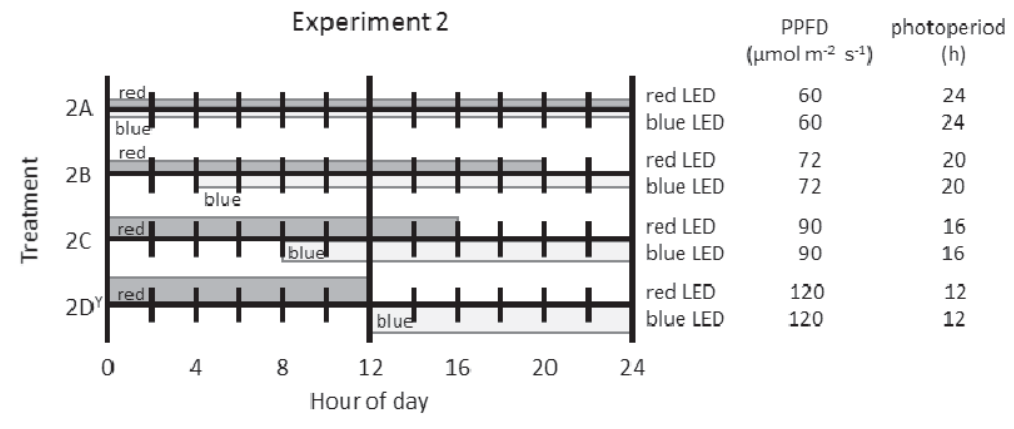

Fig. 2 Illustration of the irradiation patterns in experiment 2.

${ }^{\mathrm{Y}}$ Treatments $2 \mathrm{D}$ and RB4, BR4 in Fig. 1 were the same alternating irradiation. 
Table 1 Growth parameters of Greenwave under experiment 1-1[RB]. Treatment RB1 included simultaneous irradiation of red and blue light, and irradiation time of red was fixed and that of blue was shifted by $4 \mathrm{~h}$ and $8 \mathrm{~h}$ in treatments RB2 and RB3, respectively. Treatment RB4 was irradiation with alternating red and blue light.

\begin{tabular}{|c|c|c|c|c|c|c|c|c|}
\hline Treatment & $\begin{array}{l}\text { Total fresh } \\
\text { weight } \\
(\mathrm{g})\end{array}$ & $\begin{array}{l}\text { Fresh weight of } \\
\text { aerial parts } \\
(\mathrm{g})\end{array}$ & $\begin{array}{c}\text { Number of } \\
\text { leaves } \\
\text { (/plant) }\end{array}$ & $\begin{array}{l}\text { Stem length } \\
(\mathrm{cm})\end{array}$ & $\begin{array}{c}\text { Dry weight } \\
(\mathrm{g})\end{array}$ & $\begin{array}{l}\text { Dry matter } \\
\text { ratio } \\
(\%)\end{array}$ & SPAD & $\begin{array}{l}\text { Stomata } \\
\text { density } \\
(/ \mathrm{mm})\end{array}$ \\
\hline $\mathrm{RB} 1^{2}$ & $16.5 \mathrm{c}$ & $12.8 \mathrm{c}$ & $7.2 \mathrm{a}$ & $1.0 \mathrm{~d}$ & $0.5 \mathrm{c}$ & $3.6 \mathrm{~b}$ & $33.6 \mathrm{a}$ & $78.3 \mathrm{a}$ \\
\hline RB2 & $29.3 \mathrm{~b}$ & $24.7 \mathrm{~b}$ & $6.8 \mathrm{a}$ & $1.6 \mathrm{c}$ & $1.1 \mathrm{~b}$ & $4.4 \mathrm{a}$ & $32.0 \mathrm{a}$ & $74.0 \mathrm{a}$ \\
\hline RB3 & $35.3 \mathrm{a}$ & $27.8 \mathrm{~b}$ & $7.1 \mathrm{a}$ & $2.9 \mathrm{~b}$ & $1.2 \mathrm{~b}$ & $4.3 \mathrm{a}$ & $32.6 \mathrm{a}$ & $75.3 \mathrm{a}$ \\
\hline $\mathrm{RB} 4^{\mathrm{y}}$ & $36.7 \mathrm{a}$ & $33.3 \mathrm{a}$ & $6.7 \mathrm{a}$ & $2.4 \mathrm{a}$ & $1.5 \mathrm{a}$ & $4.4 \mathrm{a}$ & $32.8 \mathrm{a}$ & $91.0 \mathrm{a}$ \\
\hline ANOVA $^{x}$ & $* * * *$ & $* * * *$ & N.S. & $* * * *$ & $* * * *$ & $* * * *$ & N.S. & + \\
\hline
\end{tabular}

${ }^{z}$ Treatments RB1 and BR1 were the same alternating irradiation of red and blue.

${ }^{y}$ Treatments RB4, BR4 and 2D were the same simultaneous irradiation.

x **** Significant at $P<0.001$; *** significant at $P<0.005$; ** significant at $P<0.01$; $*$ significant at $P<0.05$; + Significant at $P<0.1$;

N.S. indicates non-significance. The same letters indicate no significant differences at $P<0.05$ (Ryan's multiple comparison test).

Table 2 Growth parameters of Greenwave under experiment 1-2[BR]. Treatment BR1 included simultaneous irradiation of blue and red light, and irradiation time of blue was fixed and that of red was shifted by $4 \mathrm{~h}$ and $8 \mathrm{~h}$ in treatments BR2 and BR3, respectively. Treatment BR4 was irradiation with alternating blue and red light.

\begin{tabular}{|c|c|c|c|c|c|c|c|c|}
\hline Treatment & $\begin{array}{l}\text { Total fresh } \\
\text { weight } \\
(\mathrm{g})\end{array}$ & $\begin{array}{c}\text { Fresh weight of } \\
\text { aerial parts } \\
(\mathrm{g})\end{array}$ & $\begin{array}{c}\text { Number of } \\
\text { leaves } \\
\text { (/plant) }\end{array}$ & $\begin{array}{l}\text { Stem length } \\
(\mathrm{cm})\end{array}$ & $\begin{array}{c}\text { Dry weight } \\
\text { (g) }\end{array}$ & $\begin{array}{l}\text { Dry matter } \\
\text { ratio } \\
(\%)\end{array}$ & SPAD & $\begin{array}{c}\text { Stomata } \\
\text { density } \\
(/ \mathrm{mm})\end{array}$ \\
\hline $\mathrm{BR} 1^{\mathrm{z}}$ & $15.9 \mathrm{~d}$ & $9.5 \mathrm{~d}$ & $6.3 \mathrm{a}$ & $0.9 \mathrm{~d}$ & $0.4 \mathrm{c}$ & $3.8 \mathrm{c}$ & $34.0 \mathrm{a}$ & $70.0 \mathrm{a}$ \\
\hline BR2 & $24.5 \mathrm{c}$ & $15.9 \mathrm{c}$ & $6.6 \mathrm{a}$ & $1.3 \mathrm{c}$ & $0.7 \mathrm{~b}$ & $4.6 \mathrm{~b}$ & $32.8 \mathrm{a}$ & $61.3 \mathrm{a}$ \\
\hline BR3 & $30.4 \mathrm{~b}$ & $22.3 \mathrm{~b}$ & $6.3 \mathrm{a}$ & $1.9 \mathrm{~b}$ & $1.1 \mathrm{~b}$ & $5.0 \mathrm{a}$ & $30.8 \mathrm{a}$ & $63.0 \mathrm{a}$ \\
\hline $\mathrm{BR} 4^{\mathrm{y}}$ & $38.7 \mathrm{a}$ & $27.0 \mathrm{a}$ & $6.9 \mathrm{a}$ & $2.2 \mathrm{a}$ & $1.3 \mathrm{a}$ & $4.9 \mathrm{a}$ & $30.4 \mathrm{a}$ & $59.5 \mathrm{a}$ \\
\hline ANOVA $^{x}$ & $* * * *$ & $* * * *$ & N.S. & $* * * *$ & $* * * *$ & $* * * *$ & + & N.S. \\
\hline
\end{tabular}

${ }^{z}$ Treatments BR1 and RB1 were the same alternating irradiation of red and blue.

${ }^{y}$ Treatments BR4, RB4 and 2D were the same simultaneous irradiation.

x**** Significant at $P<0.001$; *** significant at $P<0.005$; ** significant at $P<0.01$; $*$ significant at $P<0.05 ;+$ Significant at $P<0.1$;

N.S. indicates non-significance. The same letters indicate no significant differences at $P<0.05$ (Ryan's multiple comparison test).

total and fresh weight, whereas there were no significant changes in the number of leaves. Stem length increased significantly when the shift of irradiation times was larger. Dry weight of aerial parts and dry matter ratio were higher relative to the shift of irradiation times. There were few differences in SPAD and stomatal density, but these were not statistically significant.

As can be seen in Table 3, experiment RR lettuce plants irradiated with only red light at the same intensity as in experiment $\mathrm{RB}$ and $\mathrm{BR}$ also exhibited increased total fresh weight and fresh weight of aerial parts when irradiation times of red light (red2 in Fig. 1) shifted, but these gains were smaller than those observed in experiment RB and BR. Moreover, when the irradiation time was longer than $16 \mathrm{~h}$, increases in growth were small and no significant differences were detected between the total fresh weight and the fresh weight of aerial parts in treatments RR2, RR3, and RR4. Moreover, there was no significant difference in the number of leaves, and stem length was found to be significantly longer only when the shift of irradiation times was also longer. Dry weight of aerial parts was larger in proportion to the shift of irradiation times, and significant differences dry matter ratio was detected, but there was no apparent relationship between dry matter ratio and the shift of irradiation times. As with experiments $\mathrm{RB}$ and BR, no significant differences were observed for SPAD and stomatal number.

Results of experiment 2

Table 4 shows the results of experiment 2 at the time of harvest. With regards to total fresh weight and fresh weight of aerial parts, although day length was equal among all treatments, the single irradiation times of red and blue lights became longer, at which point both total fresh weight and fresh weight of aerial parts became significantly larger. However, there were few differences observed between treatment $2 \mathrm{C}$ and treatment $2 \mathrm{D}$ for these factors. There was no significant difference in the number of leaves, and stem length was only significantly longer when the shift of irradiation times was also longer. Dry weight of aerial parts was significantly larger in proportion with the shift of irradiation times. On the other hand, the dry matter ratio was significantly larger in treatment $2 \mathrm{~A}$ and no relationship between the dry matter ratio and the shift of irradiation times was detected. SPAD was small in treatment $2 \mathrm{C}$, but as with the dry matter raio, there was no significant relationship between SPAD and the shift of irradiation time. Stomata density differed somewhat, but not, significantly.

\section{DISCUSSION}

\section{Effect of shift of irradiation times of red and blue} lights on lettuce growth

Our results suggest that the shift in irradiation times of red and blue light may influence the growth of leaf lettuce, with increasing duration of irradiation leading to increased lettuce growth.

Generally, red light is known to be the most effective at activating photosynthesis, whereas blue light facilitates morphogenesis in many plant species. Bjorkman (1973) 
Table 3 Growth parameters of Greenwave under experiment 1-3[RR]. Treatment RR1 was high intensity irradiation of $240 \mu \mathrm{mol} \mathrm{m}^{-2}$ $\mathrm{s}^{-1}$ of red light for $12 \mathrm{~h}$. Treatments RR2 and RR3 were combination of high and low $\left(120 \mu \mathrm{mol} \mathrm{m}^{-2} \mathrm{~s}^{-1}\right)$ intensity irradiation of red light and dark period. Treatment RR4 was solely low irradiation with red light for the entire 24-h period.

\begin{tabular}{|c|c|c|c|c|c|c|c|c|}
\hline Treatment & $\begin{array}{l}\text { Total fresh } \\
\text { weight } \\
(\mathrm{g})\end{array}$ & $\begin{array}{c}\text { Fresh weight of } \\
\text { aerial parts } \\
(\mathrm{g})\end{array}$ & $\begin{array}{c}\text { Number of } \\
\text { leaves } \\
\text { (/plant) }\end{array}$ & $\begin{array}{l}\text { Stem length } \\
(\mathrm{cm})\end{array}$ & $\begin{array}{c}\text { Dry weight } \\
(\mathrm{g})\end{array}$ & $\begin{array}{l}\text { Dry matter } \\
\text { ratio } \\
(\%)\end{array}$ & SPAD & $\begin{array}{c}\text { Stomata } \\
\text { density } \\
(/ \mathrm{mm})\end{array}$ \\
\hline RR1 & $18.3 \mathrm{~b}$ & $12.5 \mathrm{~b}$ & $6.7 \mathrm{~b}$ & $0.9 \mathrm{~b}$ & $0.7 \mathrm{c}$ & $5.7 \mathrm{a}$ & $26.5 \mathrm{a}$ & $73.3 \mathrm{a}$ \\
\hline RR2 & $33.5 \mathrm{a}$ & $23.4 \mathrm{a}$ & $7.2 \mathrm{a}$ & $1.2 \mathrm{~b}$ & $1.0 \mathrm{~b}$ & $4.4 \mathrm{~d}$ & $24.6 \mathrm{~b}$ & $65.3 \mathrm{a}$ \\
\hline RR3 & $32.8 \mathrm{a}$ & $23.8 \mathrm{a}$ & $6.8 \mathrm{a}$ & $1.2 \mathrm{ab}$ & $1.1 \mathrm{ab}$ & $4.8 \mathrm{c}$ & $28.0 \mathrm{a}$ & $68.8 \mathrm{a}$ \\
\hline RR4 & $35.6 \mathrm{a}$ & $25.1 \mathrm{a}$ & $7.7 \mathrm{a}$ & $1.4 \mathrm{a}$ & $1.3 \mathrm{a}$ & $5.3 \mathrm{~b}$ & $28.4 \mathrm{a}$ & $68.5 \mathrm{a}$ \\
\hline ANOVA $^{z}$ & $* * * *$ & $* * * *$ & $*$ & $* * * *$ & $* * * *$ & $* * * *$ & $*$ & N.S. \\
\hline
\end{tabular}

Table 4 Growth parameters of Greenwave under experiment 2. A simultaneous or alternating irradiation of red and blue without dark period. Treatment 2A was simultaneous irradiation under red and blue light over a 24-h light period, and treatment $2 \mathrm{D}$ was alternating irradiation with red and blue light. Treatments $2 \mathrm{~B}$ and $2 \mathrm{C}$ consisted of irradiation under red, red and blue, and blue light with different overlapping period of red and blue. Daily light integral of four irradiation patters was equal and set at 10.4 $\mathrm{mol} \mathrm{m} \mathrm{m}^{-2}$.

\begin{tabular}{|c|c|c|c|c|c|c|c|c|}
\hline Treatment & $\begin{array}{c}\text { Total fresh } \\
\text { weight } \\
(\mathrm{g})\end{array}$ & $\begin{array}{c}\text { Fresh weight of } \\
\text { aerial parts } \\
(\mathrm{g})\end{array}$ & $\begin{array}{l}\text { Number of } \\
\text { leaves } \\
\text { (/plant) }\end{array}$ & $\begin{array}{l}\text { Stem length } \\
\quad(\mathrm{cm})\end{array}$ & $\begin{array}{c}\text { Dry weight } \\
(\mathrm{g})\end{array}$ & $\begin{array}{l}\text { Dry matter } \\
\text { ratio } \\
(\%)\end{array}$ & SPAD & $\begin{array}{c}\text { Stomata } \\
\text { density } \\
(/ \mathrm{mm})\end{array}$ \\
\hline $2 \mathrm{~A}$ & $44.2 \mathrm{c}$ & $32.4 \mathrm{c}$ & $9.2 \mathrm{a}$ & $2.2 \mathrm{c}$ & $1.8 \mathrm{c}$ & $5.5 \mathrm{a}$ & $28.0 \mathrm{a}$ & $149 \mathrm{a}$ \\
\hline $2 \mathrm{~B}$ & $54.2 \mathrm{~b}$ & $42.0 \mathrm{~b}$ & $8.5 \mathrm{a}$ & $3.4 \mathrm{~b}$ & $2.2 \mathrm{~b}$ & $5.2 \mathrm{~b}$ & $28.0 \mathrm{a}$ & $154 \mathrm{a}$ \\
\hline $2 \mathrm{C}$ & $61.6 \mathrm{a}$ & $51.0 \mathrm{a}$ & $8.7 \mathrm{a}$ & $4.7 \mathrm{a}$ & $2.5 \mathrm{a}$ & $4.9 \mathrm{c}$ & $24.9 \mathrm{a}$ & $163 \mathrm{a}$ \\
\hline $2 \mathrm{D}^{\mathrm{z}}$ & $61.3 \mathrm{a}$ & $52.5 \mathrm{a}$ & $8.5 \mathrm{a}$ & $4.7 \mathrm{a}$ & $2.6 \mathrm{a}$ & $4.9 \mathrm{c}$ & $29.1 \mathrm{a}$ & $158 \mathrm{a}$ \\
\hline ANOVA $^{y}$ & $* * * *$ & $* * * *$ & N.S. & $* * * *$ & $* * * *$ & $* * * *$ & + & N.S. \\
\hline
\end{tabular}

${ }^{z}$ Treatments $2 \mathrm{D}$, RB4 and BR4 were the same simultaneous irradiation. ${ }^{\mathrm{y}} * * * *$ Significant at $P<0.001$; *** significant at $P<0.005$;

** significant at $P<0.01$; * significant at $P<0.05$; + Significant at $P<0.1$; N.S. indicates non-significance. The same letters indicate no

significant differences at $P<0.05$ (Ryan's multiple comparison test).

reported that of red, green, and blue light, red light was the most effective in increasing the photosynthetic quantum yield of plants in general; in addition, this study showed that photosynthetic rates of lettuce growing under red light were greater than those of lettuce growing under blue light. Moreover, Hirai et al. (2006) revealed that stem elongation of leaf lettuce was promoted under red, green, and bluegreen light, but was markedly suppressed under blue light. Stutte and Edney (2009) studied that leaves developed horizontally under blue light, a morphogenetic configuration that increased the amount of light absorption by the lettuce plants. Kim et al. (2004) reported when lettuce plants were grown under four different treatments, red and blue LEDs (RB), red and blue LEDs with green fluorescent lamps (RGB), green fluorescent lamps (GF), and cool white fluorescent lamps (CWF), the dry matter accumulation for plants grown under RB and CWF was similar, indicating that normal growth for lettuce could be achieved with only red and blue photons. Owing to the aforementioned reasons, we concluded that because red light improves photosynthesis and blue light induces lettuce plants to assume the optimum morphogenetic form to receive light, growing lettuce under alternating regimes of red and blue lights represents the most effective course.

Moreover, experiments RB and BR show that the shift in irradiation times of red and blue light significantly facilitates the growth of lettuce (Tables 1 and 2), which may be because the alternation of red and blue lights enhances the effects of red and blue lights discussed above. Shoji et al. (2001) reported that when lettuce was irradiated with white light, as the main light source and blue light as supplementary lighting during the dark period, plants exhibited a significant increase in fresh weight, dry matter, and leaf number when exposure to supplementary lighting was reduced. In addition, Hanyu and Shoji (2002) showed that when spinach was irradiated with blue light shortly after the end of the dark period, dry weight, plant height, and SLA increased significantly. Moreover, Sung and Takano (1997) observed that when cucumber seedlings were irradiated with blue light for $2 \mathrm{~h}$ prior to daylight, both the transpiration and photosynthetic rates of cucumber seedlings increased, as did fresh weight; stem length and leaf area assumed, optimum morphogenetic configuration for light reception. In light of the evidence indicating that irradiation with blue light during the dark period promotes lettuce growth, it may be a valid assumption that the differences in lettuce growth observed in our study were because of the increase in irradiation time of blue light during the dark period being longer because of the irradiation shift. Furthermore, experiment RR shows that there was little growth acceleration when lettuce plants were irradiated only with red light under equal light intensity (Table 3 ).

These results show that the irradiation pattern that uses a combination of red and blue lights and that shifts the irradiation times of red and blue lights greatly influences lettuce growth acceleration. In previous research, the cultivation experiment that examined the effects of single, simultaneous, and alternating irradiations with red and blue LED lights on leaf lettuce growth demonstrated that irradiation with both red and blue lights were more effective than either alone for lettuce growth (Shimokawa et al., 2013). Additionally, lettuce plants grown under red and blue lights 
exhibited enhanced growth compared to lettuce plants grown under only red lights (Hoeneckeet al., 1992). Thus, in regards to leaf lettuce cultivation, irradiation regimes that use a combination of red and blue lights is more effective than are irradiation regimes based solely on red light.

In this study, the effect on alternating and simultaneous irradiation patterns under the same energy input to the light source was investigated. For that reason, there was a treatment in which the light intensity became $240 \mu \mathrm{mol} \mathrm{m}^{-2}$ $\mathrm{s}^{-1}$. Although there is a concern that this may be too strong for lettuce at nursery stage, this is an issue left for the future.

Effects of simultaneous or alternating irradiation of red and blue light on lettuce growth under equal day length and light integral

In the previous section, we concluded that the shift in irradiation times of red and blue light promotes lettuce growth, but the cause of these effects may be mere prolongation of day length by the shift of irradiation times. We conducted experiment 2 to determine whether the cause of growth promotion is due not to prolongation of day length but the shift in irradiation times. Table 4 shows that alternating irradiation with red and blue lights for 12-h periods promoted lettuce growth more effectively than did simultaneous irradiation for $24 \mathrm{~h}$. Further, the cultivation experiment examining the effects of simultaneous, and alternating irradiations with red and blue light on leaf lettuce growth demonstrated that a pattern of alternating irradiation between red and blue light enhanced lettuce growth most effectively, when the fresh weight of lettuce plants under alternating irradiation regimes was about 1.6 times larger than the fresh weight of plants grown under simultaneous irradiation (Shimokawa et al., 2014), and Ohtake et al. (2014; 2015) showed alternating irradiation with red and blue light increased fresh weight of leaf lettuce compared to simultaneous light. Alternating irradiation between red and blue lights is thus more effective at promoting Greenwave than is simultaneous irradiation.

Moreover, Table 4 shows that there were few differences in growth response between plants in treatment $2 \mathrm{C}$ and treatment 2D. First, in regards to this phenomenon, integrating day length equally may reduce the effects of the shift of irradiation time between red and blue lights. Second, light intensities differed among 4 treatments in experiment 2 , however, the underlying mechanism of this phenomena remains unknown. Although treatment 2D, RB 4, and BR 4 have the same light condition, growth of lettuce was greater in 2D than BR4 and RB4. This may be caused by changing cultivation trays and cultivation panels in experiment 2. Okamoto et al. (1997) investigated the effects of different ratios of red and blue light on morphology of lettuce seedlings under mixture light of blue and red provided by LEDs at a light intensity of $80 \mu \mathrm{mol} \mathrm{m} \mathrm{m}^{-2} \mathrm{~s}^{-1}$, and they observed that morphological anomalies did not occur with $24 \mu \mathrm{mol} \mathrm{m} \mathrm{m}^{-2} \mathrm{~s}^{-1}$ or more of blue light. In this study, although intensity of blue light was as low as 60 and $72 \mu \mathrm{mol} \mathrm{m} \mathrm{m}^{-2} \mathrm{~s}^{-1}$ under the light conditions of $2 \mathrm{~A}$ and $2 \mathrm{~B}$ respectively, no morphological abnormality was observed at harvest time.
The cultivation experiment examining the effect of red and blue LED lights on cos lettuce growth demonstrated that the pattern containing single irradiation with blue light caused the stem extension and the longer cycle of alternating irradiations with red and blue light also led to promote stem extension (Jishi et al., 2015). Thus, day length and single irradiation time of blue light are strongly associated with growth acceleration, factors that we intend to focus on in future experiments in order to establish the optimal irradiation pattern.

In this study, the results showed that alternating irradiation between red and blue lights resulted in increased lettuce growth. However, Jao and Fang (2004) reported that when potato plantlets were cultivated under simultaneous and alternating patterns of irradiation with blue and red lights, simultaneous irradiation with blue and red lights led to higher rates of potato plantlets growth compared to alternating irradiation. Thus, in terms of growth response, different plant species appear to respond in different ways to simultaneous and alternating patterns of irradiation. Further experiments are therefore needed in order to determine the optimal irradiation patterns in other species.

\section{CONCLUSIONS}

Our results indicate that the irradiation patterns of red and blue light influence the growth of leaf lettuce (Lactuca sativa L."Greenwave"), and that alternating irradiation leads to the highest yields of leaf lettuce. The causes of growth promotion can be attributed to the relationship between the length of time of red-light irradiation and leaf lettuce growth, whereby the longer irradiation time of red light leads to increased lettuce growth, and that irradiation with blue light during the dark period enhanced lettuce growth.

Moreover, day length, light intensity, and long periods of irradiation with blue light during the dark period are important factors of growth acceleration, suggesting that an alternating irradiation between red and blue lights is the optimal pattern for increasing yields of Greenwave.

\section{REFERENCES}

Bjorkman, O. 1973. Comparative studies on photosynthesis in higher plants. Photophysiology 8: 1-63.

Ebisawa, M., Shoji, K., Kato, M., Shimomura, K., Goto, F., Yoshihara, K. 2008. Effect of supplementary lighting of UV-B, UV-A, and blue light during the night on growth and coloring in red-leaf lettuce. J. SHITA 20: 158-164.

Hanyu, H., Shoji, K. 2000. Effects of blue light and red light on kidney bean plants grown under combined radiation from narrow-band light source. Environ. Control Biol. 38: 13-24.

Hanyu, H., Shoji, K. 2002. Acceleration of growth in spinach by short-term exposure to red and blue light at the beginning and at the end of the daily dark periods. Acta Hortic. 580: $145^{-150 .}$

Hirai, T., Amaki, W., Watanabe, H. 2006. Effects of monochromatic light irradiation by LED on the internodal stem elongation of seedlings in eggplant, leaf lettuce and sunflower. J. SHITA 18: 160-166.

Hoenecke, M. E., Bula, R. J., Tibbitts, T. W. 1992. Importance 
of 'blue' photon levels for lettuce seedlings grown under redlight-emitting diodes. HortScience 27: 427-430.

Inada, K., Yabumoto, Y. 1989. Effects of light quality, daylength and periodic temperature variation on the growth of lettuce and radish plants. Jpn. J. Crop Sci. 58: 689-694.

Jao, R. C., Fang, W. 2004. Growth of potato plantlets in vitro is different when provided concurrent versus alternating blue and red light photoperiods. HortScience 39: 380-382.

Jishi, T., Matsuda, R., Fujiwara, K. 2015. A kinetic model for estimating net photosynthetic rates of cos lettuce leaves under pulsed light. Photosynth. Res. 124: 107-116.

Kim, H., Goins, G. D., Wheeler, R. M., Sager, J. C. 2004. Stomatal conductance of lettuce grown under or exposed to different light qualities. Ann. Bot. 94: 691-697.

Matsumoto, T., Itoh, H., Shirai, Y., Shiraishi, N., Uno, Y. 2010. Effects of light quality on growth and nitrate concentration in lettuce. J. SHITA 22: 140-147.

Ohtake, N., Yoneda, H., Suzuki, M., Shigyo, M., Furuyama, S., Hikosaka, S., Goto, E. 2014. Growing analysis of leaf lettuce cultivated under LED irradiation alternating from red and blue. Hortic. Res. (Japan) 13 (Suppl.2): 187.

Ohtake, N., Yoneda, T., Suzuki, H. 2015. Comparison of plant growth and electrical power consumption between red/blue led and fluorescent lamp in a plant factory. J. SHITA 27: 213218.

Okamoto, K., Yanagi, T., Kondo, S. 1997. Growth and morphogenesis of lettuce seedlings raised under different combinations of red and blue light. Acta Hortic. 435: 149157.

Saito, Y., Shimizu, H., Nakashima, H., Miyasaka, J., Ohdoi, K. 2012. Comparison of the effects of monochromic red light and mixed light on the growth of lettuce. J. SHITA 24: 25-30.

Shimokawa, A., Ara, H., Tonooka, Y., Yamauchi, N., Shigyo, M. 2013. Effect of LED Irradiation alternating from red to blue on growth of leaf lettuce. Hortic. Res. (Japan) 12 (Suppl.1): 156.

Shimokawa, A., Tonooka, Y., Matsumoto, M., Ara, H., Suzuki, H., Yamauchi, N., Shigyo, M. 2014. Effect of alternating red and blue light irradiation generated by light emitting diodes on the growth of leaf lettuce. bioRxiv.2014. doi: http://dx.doi.org/ $10.1101 / 003103$

Shoji, K., Hanyu, H., Shimizu, H. 2001. Effects of supplementary lighting of blue-light during the night on anthocyanin synthesis and growth of red-leaf lettuce (Lactuca sativa $\mathrm{L}$.). Abiko Research Laboratory Rep.No.U01009

Stutte, G. W., Edney, S. 2009. Photoregulation of bioprotectant content of red leaf lettuce with light-emitting diodes. HortScience 44: 79-82.

Sung, K., Takano, T. 1997. Effects of supplemental blue- and red-lights in the morning twilight on the growth and physiological responses of seedlings. J. SHITA 35: 261-265. 